\section{MEASUREMENT OF IONIZING RADIATIONS IN MEDICINE AND BIOLOGY}

Radiation Dosimetry

Edited by Gerald J. Hine and Gordon L. Brownell. Pp. xiv +932. (New York: Academic Press, Inc.; London: Academic Books, Ltd., 1956.) 22 dollars; $157 s$.

7 HE scope of this book is at the same time both narrower and wider than its title suggests. It is narrower in that the book deals only with ionizing radiations (including neutrons because the secondary radiations produce ionization) and these chiefly from a biological and medical point of view. But at the same time, not only is measurement of radiation included, but also some space is given to the production of radiation, its biological action and some of the technical aspects of the medical applications. The general reader might well foel a little surprised at finding the dosimetry of ionizing radiations to be such a complicated subject requiring such a large volume as this for its exposition. The essential idea of dose as the energy dissipated locally at a point in a medium seems so simple. But it should be remembered that it was not until 1953 that such a unit of dose, the rad (100 ergs per gram), was finally agreed and adopted internationally. The history of dose units in the preceding fifty-odd years is one of practical compromises imposed by limitations of the available techniques of measurement. The earlier workers knew what they wanted but the ideal was unattainable. The amounts of energy absorbed in a medium were generally far too small for successful direct measurement. Hence the recourse to measurement of air ionization and the emergence of the röntgen as a unit which did duty fairly well as a measure of dose and of exposure. Even to-day, the ionization method of dose measurement, based on the BraggGray theory, remains pre-eminent, but even here finality has not yet been reached : witness the uncertainty in this volume as to the precise numerical relation between röntgen and rad.

There are now, however, several other practicable methods of measuring radiation dose, developed under the stimulus of the new discoveries in atomic energy. A need existed for a collected account of all the available methods, and hence the present book has been written. It is the work of well-known experts from both sides of the Atlantic, who have been responsible either singly or in groups for one or more of its eighteen chapters. The editors have found a very satisfactory answer to what must have been a difficult decision by making each chapter largely complete in itself. Inevitably, during a complete perusal of the book some repetition is apparentBethe's equation for rate of energy loss seems to appear on countless occasions-but undoubtedly this plan makes the book more convenient for normal use.

There are three moin sections in the book. The first, about one-sixth of the total, gives an admirable summary of fundamental principles of dosimetry. It also includes a very condensed summary of the general biological effects of radiation, but it is questionable whether this serves any useful purpose in a book on dosimetry. The remainder of the book is divided about equally between a section on instrumentation and one on applications, and constitutes the book's main importance, for there is so much here that is new. All the various techniques are critically reviewed and the latest developments dealt with fully. At the end of each chapter there is a comprehensive and up-to-date bibliography. The general level of the contributions is very high, with a gratifying freedom from errors and half-truths. The standard of production of the book is superb, the figures and their arrangement are excellent, likewise the index, and the proof-reading has been remarkably thorough. This book is a very significant contribution to a subject of increasing importance and all concerned in it deserve thanks.

$$
\text { G. J. NEARY }
$$

\section{THE METAZOAN PARASITES OF ANIMALS}

\section{Mönnig's Veterinary Helminthology and Entom-} ology

Fourth edition by Dr. Geoffrey Lapage. Pp. xvi+ $512+24$ plates. (London: Baillière, Tindall and Cox, Ltd., 1956.) 42s, net.

HIS new edition of Mönnig's standard text-book has been eagerly awaited, as it is nine years since the third edition appeared and much information on animal parasites has come to light during that time.

It is obvious that Dr. Lapage has had the interest of both student and teacher at heart, for he has endeavoured, wherever possible, to simplify the classification and recognition of the various parasites, particularly in the section on arthropods. Instead of footnotes, a general bibliography with references up to 1956 is provided at the end. The original text figures have been retained and nineteen excellent photographs added. 'The plates showing the eggs of worm parasites are now on art paper, and these, together with the section on technique and diagnosis, have been transferred to the end of the book. These egg plates might be improved further by including diagrams of larvæ which are passed out in the fæces and of the infective larve.

As in the former editions, this book is divided into four sections. Section $I$ has been completely rewritten and extended by several pages and deals with types of parasitism, typical life-histories, effects of parasitic life on the parasites and on their hosts, and the resistance by the hosts to parasites. Section 2, on helminths, has been extended by twenty-six pages and revised with the assistance of Dr. Mönnig himself. Four genera and thirteen species have been added, and life-histories, treatments and control measures have been brought up to date. Considering the growing importance of Nematodirus battus, one would have liked more information on its morphology and a drawing of the egg included in the egg plate for sheep.

It is to Section 3, on arthropod parasites, that Dr. Lapage has given his particular attention. Much of it has been rewritten and re-classified, more than thirty species added and names altered where necessary to conform with modern nomenclature. Control measures also have been revised, though the strength of the D.D.T. dust given on p. 398 for the control of lice in cattle seems rather too weak to be effective. Section 4 deals with technique and diagnosis and now includes the interpretation of worm egg counts, additional methods for fixing and storing trematodes, 